\title{
REVIEW
}

\section{Filling the Knowledge Gap in Diabetes Management During Ramadan: the Evolving Role of Trial Evidence}

\author{
Saud Al Sifri · Kashif Rizvi
}

Received: February 16, 2016 / Published online: April 18, 2016

(C) The Author(s) 2016. This article is published with open access at Springerlink.com

\section{ABSTRACT}

Muslim patients with type 2 diabetes (T2D) who fast during Ramadan face challenges in diabetes management due to substantial alterations in lifestyle and treatment that frequently accompany the decision to fast. International guidelines for treating T2D do not fully address the clinical issues unique to fasting, and other guidance documents lack the large and high-quality evidence base available for non-fasting conditions. We reviewed 10 randomized controlled trials and 20 observational studies in T2D during Ramadan to assess the quality of evidence and identify issues in trial design that should be addressed in future studies. Results indicated that heterogeneity in key aspects of trial design precluded meaningful comparisons across

Enhanced content To view enhanced content for this article go to http://www.medengine.com/Redeem/ 04B4F06039A930B8.

S. Al Sifri $(\bowtie)$

Endocrinology Department, Alhada Military

Hospital, Taif, Saudi Arabia

e-mail: saudnafa@hotmail.com

K. Rizvi

Specialized British Medical Unit, Mazaya Clover Centre, Jabriya, Kuwait studies. These included patients' baseline treatment at entry; use of a cutoff for glycemic control [glycated hemoglobin $\left(\mathrm{HbA}_{1 \mathrm{c}}\right)$ ] for eligibility; exclusion of patients with a history of recurrent hypoglycemia or hypoglycemia unawareness, or with other serious systemic diseases; duration of treatment and follow-up, selection of safety versus efficacy as primary end point; and definition and measurement of those end points. Fructosamine was rarely used as an efficacy end point, despite the advantage of reflecting glycemic control over a period more closely aligned with the duration of Ramadan fasting than $\mathrm{HbA}_{1 \mathrm{c}}$. Adherence to treatment, definition and adherence to fasting, and changes in diet and exercise were reported inconsistently, and when reported, not in a fashion that would allow adequate control of confounding due to these variables. Despite a large body of evidence demonstrating their safety and efficacy in non-fasting populations, only two trials reported data for glucagon-like peptide-1 analogs, and neither involved a head-to-head comparison against dipeptidyl peptidase- 4 inhibitors. More rigorous studies using trial designs suited to the unique conditions of a fasting population and 
capturing both standardized efficacy and safety end points are needed to provide better guidance to optimal treatment of T2D during Ramadan fasting.

Funding: Novo Nordisk AG.

Keywords: Diet; End points; Fasting; Hypoglycemia; Incretins; Ramadan; Sulfonylurea; Type 2 diabetes

\section{INTRODUCTION}

Fasting during the holy month of Ramadan is an important religious obligation for observant Muslims, and it is estimated that about $79 \%$ of Muslims with type 2 diabetes (T2D) will fast during Ramadan [1]. Typically, fasting requires refraining from eating, drinking, and use of oral and parenteral medications during the period from $75 \mathrm{~min}$ before sunrise to $15 \mathrm{~min}$ after sunset [2-4]. Because the occurrence of Ramadan follows the lunar calendar, which is shorter than the Gregorian calendar, the holy month is observed 10-11 days earlier each year. When Ramadan falls during the summer months, the duration of fasting each day could potentially exceed $20 \mathrm{~h}$ for people living in northern latitudes where the day is longer $[4,5]$.

Extended fasting of any sort counteracts some of the main principles of good diabetes management, which traditionally involve careful planning of dietary intake, taking regular meals and exercise, and aligning these activities with any medical treatments used to lower blood glucose, to avoid excessive hyperglycemia and hypoglycemia. Introducing fasting while also using glucose-lowering medications may further challenge diabetes management, particularly with respect to hypoglycemia. Indeed, medical opinion remains divided about whether it is safe, even for people with well-controlled diabetes, to fast during Ramadan [6-9]. These safety concerns are supported by some empirical data. For example, one large survey of 11,173 Muslims with $\mathrm{T} 2 \mathrm{D}, 78.4 \%$ of whom were treated with oral antidiabetic drugs (OADs), indicated that fasting during Ramadan was associated with a 7.5-fold greater incidence of severe hypoglycemia $(0.03 \pm 0.28$ vs. $0.004 \pm 0.02$ episodes/month, $P<0.0001$, for fasting vs. non-fasting periods, respectively) [1]. Fasting was also associated with a greater incidence of severe hyperglycemia $(0.05 \pm 0.35$ vs. $0.01 \pm 0.05$ episodes/month, respectively, $P<0.0001)$. Nevertheless, Ramadan is an integral part of life for many Muslims, with benefits for physical, mental, and social well-being [10], and many Muslims with T2D choose to fast during Ramadan, some against medical advice.

Given that the growing Muslim population of the world often overlaps with regions where the incidence of T2D is also increasing rapidly $[11,12]$, there is a compelling need for a more rigorous evidence base to help clinicians make informed decisions on how to best treat patients with T2D who wish to fast. For the general population of patients with $\mathrm{T} 2 \mathrm{D}$, several major guideline documents have been published, which include recommendations for newer treatments, such as drugs of the incretin class [glucagon-like peptide-1 (GLP-1) analogs and dipeptidyl peptidase-4 (DPP-4) inhibitors], which have been shown to have a favorable balance of safety and efficacy [13, 14].

Although a variety of other guidance documents have been published offering recommendations on diabetes management during religious fasting $[3,15-25]$, there is currently no gold standard based on comprehensive, up-to-date, evidence-based recommendations. A major reason is that evidence from clinical trials in non-fasting 
populations, which form the basis for major international diabetes treatment guidelines, is not completely transferable to populations who engage in religious fasting. This is because fasting during Ramadan typically results in a variety of changes in lifestyle and treatment, discussed below, which may disrupt typical diabetes management practices.

The most consistent changes occurring during Ramadan fasting include alterations in the typical between-meal interval, reduced frequency of meals (e.g., two per day, instead of three $[23,26])$, the type of food eaten (e.g., more fried foods and/or the proportion of energy from carbohydrates such as dates, juices, and sweets vs. other macronutrients) [11], and eating a larger volume of food at a given time if only two meals are consumed. With respect to consistency of exercise, long-night Taraweeh prayers lasting 1-2 h, although not mandatory, can be strenuous [21]. It has also been noted that fasting during Ramadan may be associated with changes in sleep patterns and quality, alertness, and irritability [5]. It is possible, although currently speculative, that the stress of coping with these additional challenges for an entire month could further compromise a person's ability to manage their diabetes effectively.

For patients using OADs, it can be difficult to coordinate taking medications that must or may be administered more than once daily (e.g., some sulfonylurea s or glinides) with an altered meal schedule [27]. Maintaining adequate glycemic control when using OADs may be further complicated if accompanied by arbitrary patient-initiated changes in dose, frequency of dosing, and/or timing of administration of OADs relative to meals, all of which are believed to be common during Ramadan [27-29].
There are some promising data on the efficacy and safety of DPP-4 inhibitors and GLP-1 analogs of the incretin class during Ramadan, although results have not always been entirely consistent. One analysis of 16 published studies concluded that there was some evidence that DPP-4 inhibitors led to fewer episodes of hypoglycemia than sulfonylureas. The analysis, while only analyzing one trial with a GLP-1 analog, indicated that GLP-1 analogs also provide clinical benefits during Ramadan compared with sulfonylureas [30]. Schweizer et al. [31] also concluded that DPP-4 inhibitors may be safe and effective, but a pooled analysis of data from three randomized controlled trials (RCTs) suggested that sulfonylureas had similar incidence of hypoglycemic episodes compared to DPP-4 inhibitors during Ramadan [32].

Compared to DPP-4 inhibitors, there is less information regarding the use of GLP-1 analogs in T2D during Ramadan, with only two trials currently published. One RCT reported a greater proportion of subjects achieving the composite end point of glycated hemoglobin $\left(\mathrm{HbA}_{1 \mathrm{c}}\right)$ $<7.0 \%$ and weight loss with no severe hypoglycemic events for liraglutide compared to sulfonylureas (both in combination with metformin) [33]. Another RCT has demonstrated fewer hypoglycemic episodes with equivalent glycemic control and greater body weight reduction for liraglutide versus sulfonylurea (both in combination with metformin) [34]. With regard to comparisons of the two classes of incretin drugs, there are currently no trials comparing DPP-4 inhibitors and GLP-1 analogs directly during Ramadan.

Choosing the optimal treatment for patients with T2D requires a robust evidence base; but at least quantitatively, the volume of evidence from clinical trials during Ramadan fasting is 
much more limited than that for the general population of people with T2D. Furthermore, the quality of the available information, as well as what might be needed to establish a more reliable evidence base, is not clear, and some results appear to be contradictory. Therefore, we conducted this review to critically examine published evidence from both RCTs and observational studies in T2D during Ramadan, with the goal of summarizing the degree to which they are consistent in key areas of trial design. An additional goal was to assess the comparability of results across trials and identify inconsistencies or deficiencies that should be addressed in the design of future studies. Thus, given our emphasis on understanding the important contribution of trial design to the evidence base, efficacy and safety results per se from individual trials will not be discussed in detail here.

\section{METHODS}

PubMed was searched for the terms "Ramadan" and "diabetes" in either the title or abstract from 1980 to the present. In total, 197 citations were retrieved. Abstracts were reviewed, and papers describing either randomized trials or observational studies of non-insulin treatments in T2D during Ramadan and reporting efficacy and/or safety were retained. In addition, the bibliographies of retrieved papers were manually searched to identify any additional relevant studies. The retrieved studies were characterized with respect to key aspects of study design and methodology (e.g., populations, OAD treatments used, duration of trial and period of assessment, choice of end points and measurement of those end points) that are particularly pertinent to the unique aspects of trials of diabetes treatments during religious fasting, as well as the consistency and completeness of reporting of these features.

This article is based on previously conducted studies, and does not involve any new studies of human or animal subjects performed by any of the authors.

\section{RESULTS}

\section{Design and Methodological Characteristics of Studies}

The key features of study design are presented in Table 1 for 10 RCTs and in Table 2 for 20 observational studies.

\section{Treatments Studied}

Sulfonylureas and drugs of the incretin class appear to be the most widely studied non-insulin treatments in comparative trials during Ramadan. However, individual RCTs sometimes did not differentiate among the different sulfonylureas used by patients, simply grouping different sulfonylureas (e.g., gliclazide, glibenclamide, glimepiride; glipizide) together as a class when reporting results (Table 1). This may not be appropriate, as these drugs have durations of actions of $12-18 \mathrm{~h}, 12-16 \mathrm{~h}, 12-24 \mathrm{~h}$, and $6-10 \mathrm{~h}$, respectively [35]. In addition, pooled data from a number of agents in the sulfonylurea class mask the different hypoglycemia risks associated with the individual drugs, as newer generation sulfonylureas such as gliclazide are associated with a lower hypoglycemia risk compared with other sulfonylureas [36]. In fact, a meta-analysis showed no difference in hypoglycemia incidence with gliclazide compared with DPP-4 inhibitors [37]. By contrast, results for drugs of the incretin class 


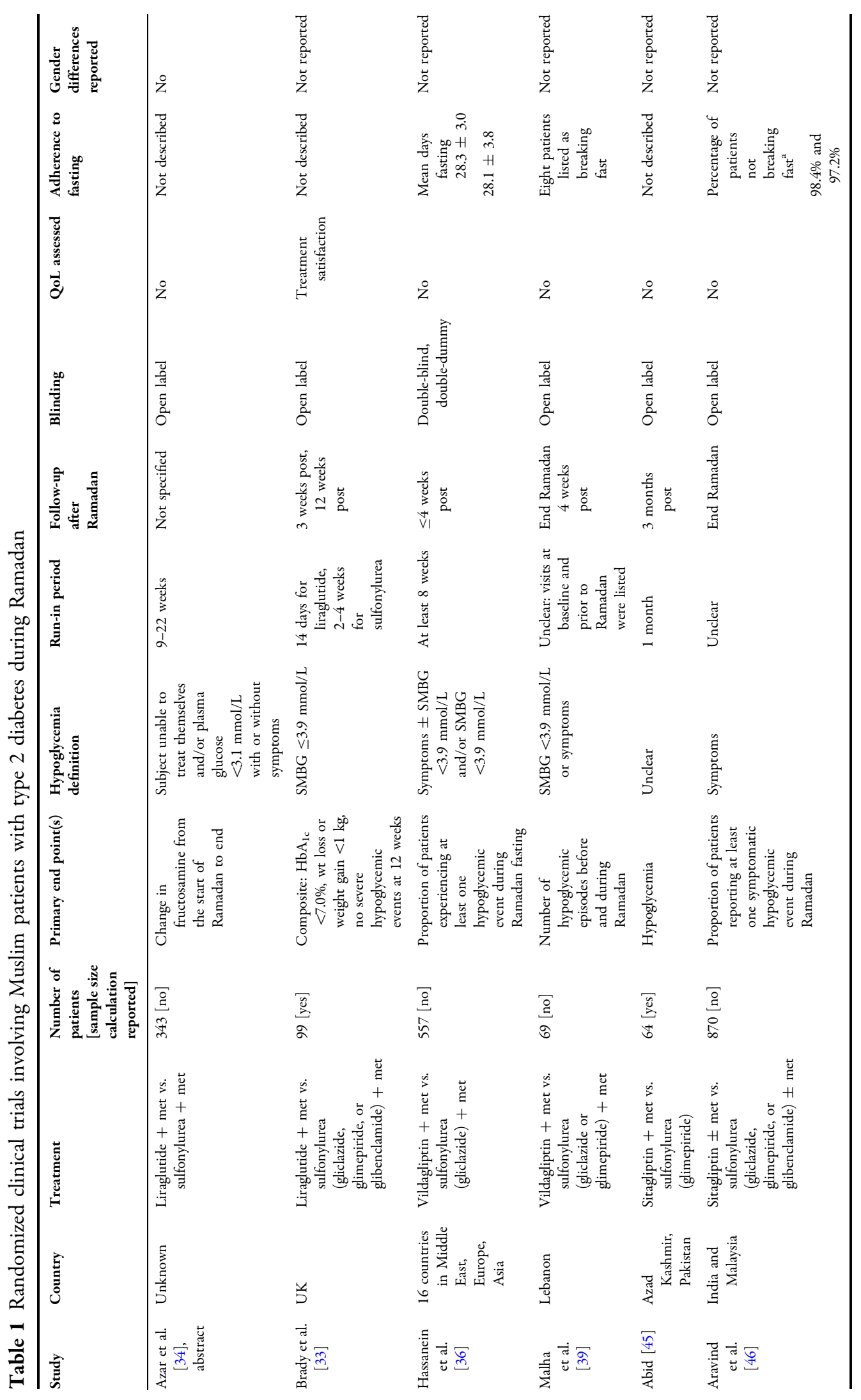




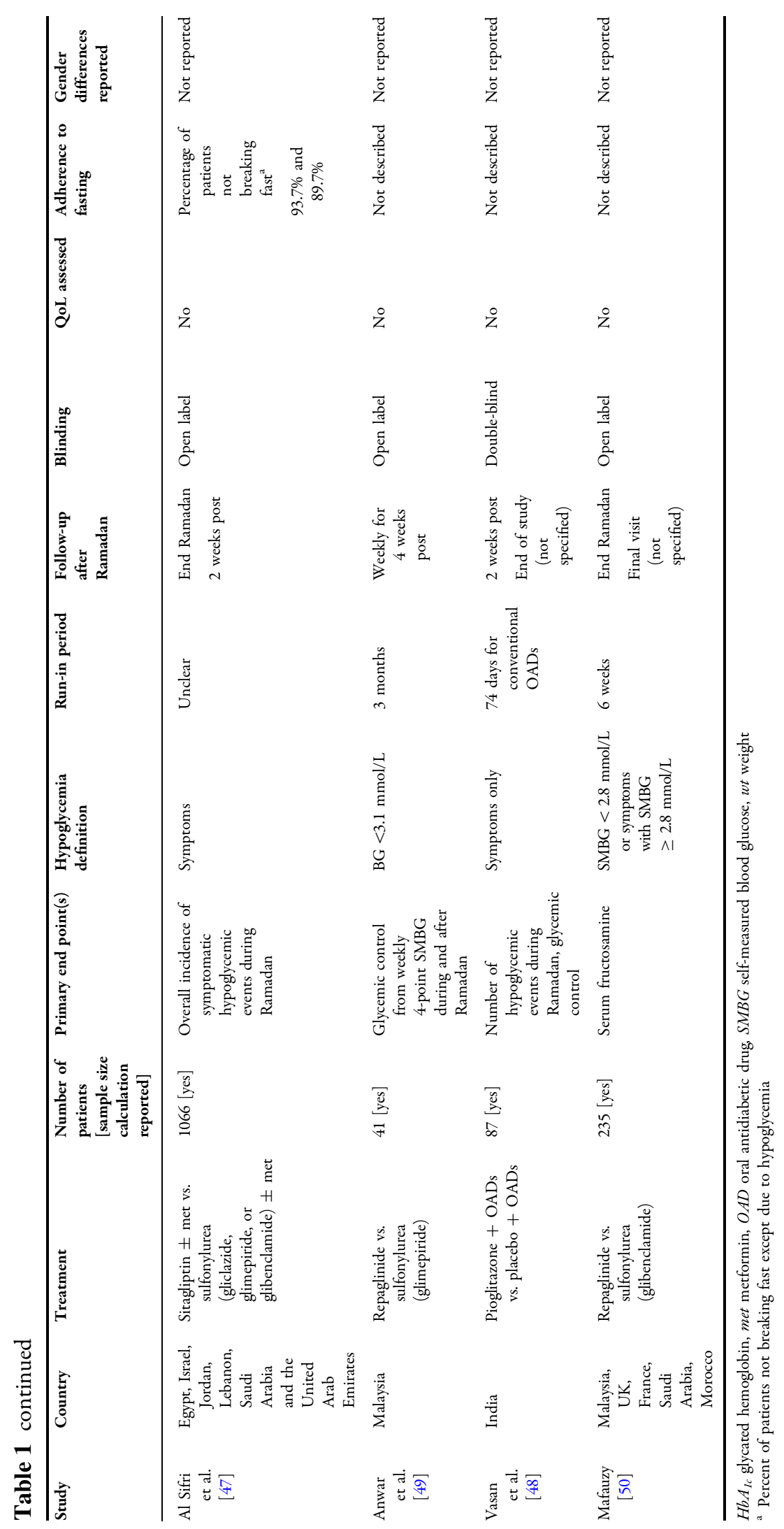




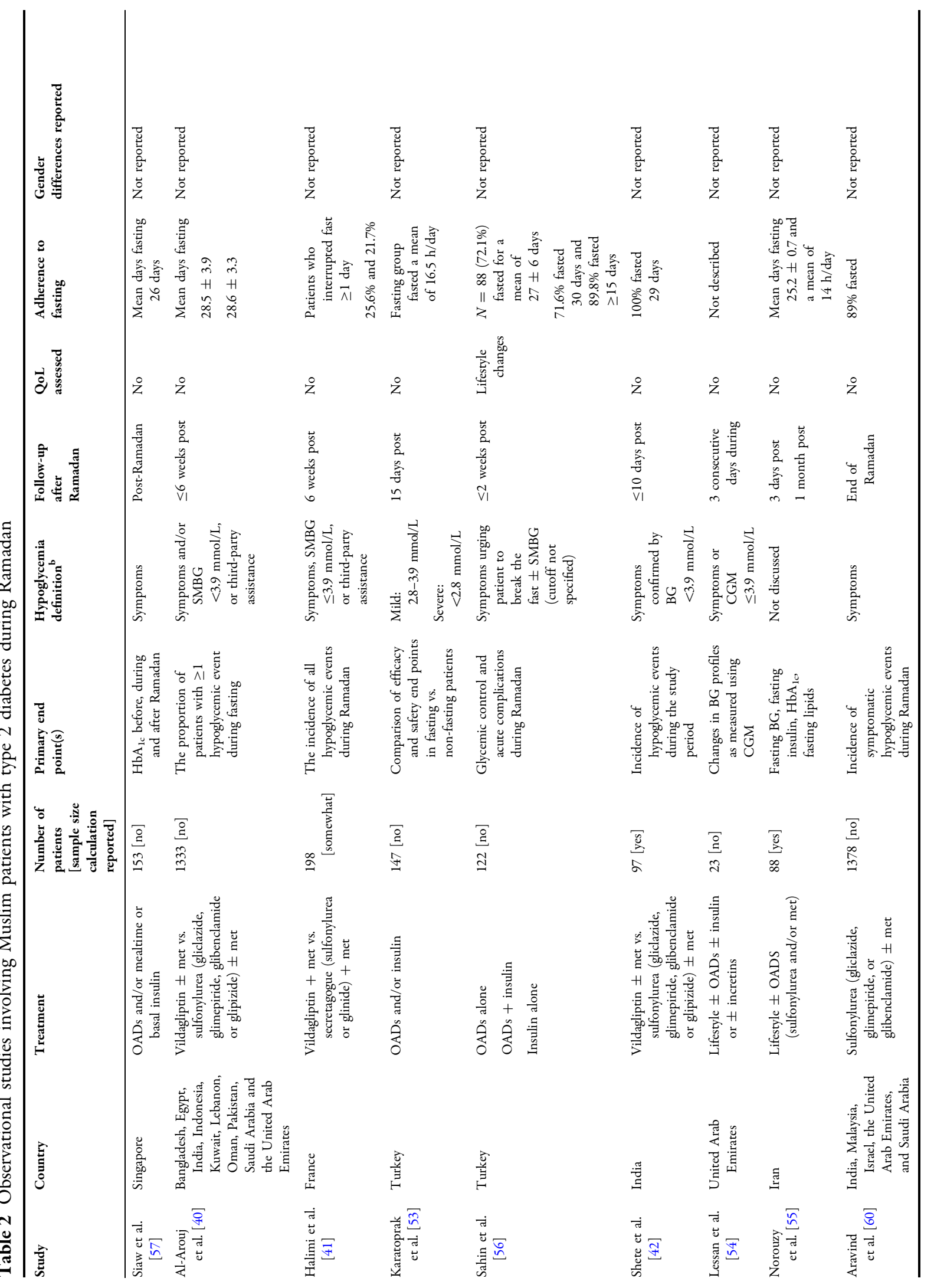




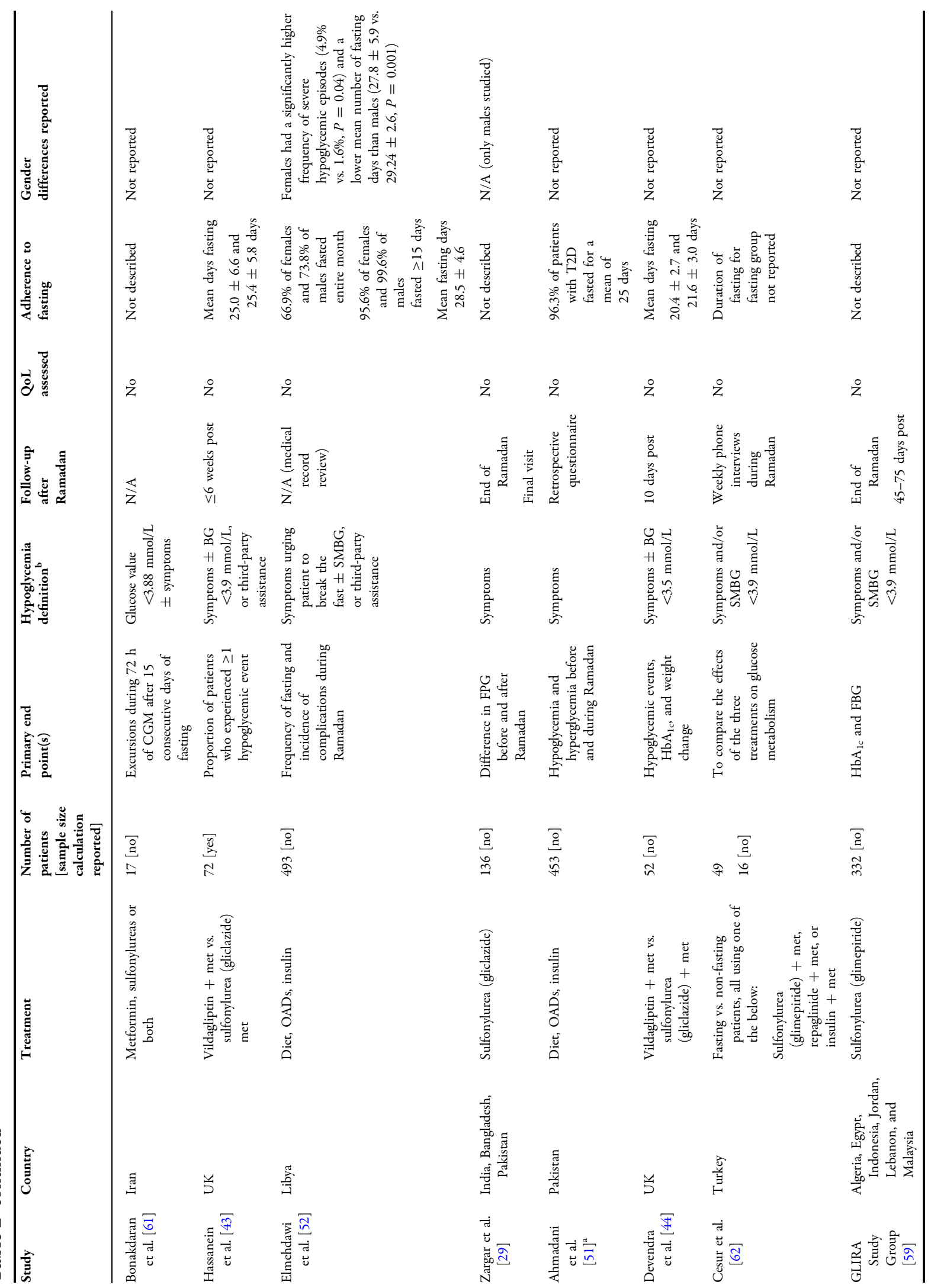




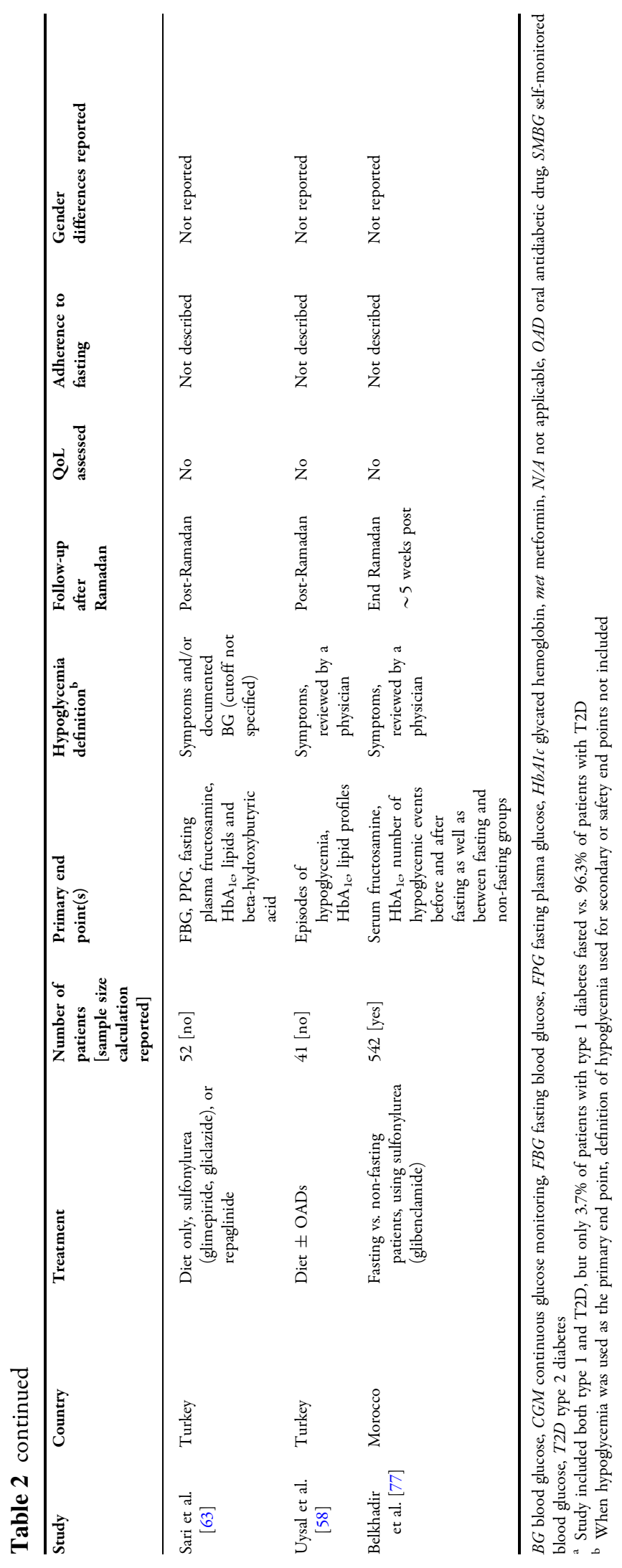


have been reported individually for vildagliptin (two RCTs [38, 39] and five observational studies [40-44]) for sitagliptin (three RCTs [45-47]) and liraglutide (two RCTs [33, 34]). The use of metformin was common, but not universal (Table 1). Both RCTs using liraglutide included metformin [33, 34], as did the two studies using vildagliptin [38, 39] and one of three RCTs using sitagliptin [45]. However, metformin was optional for two of the RCTs using sitagliptin $[46,47]$ and one trial using pioglitazone [48]. Metformin was not used in the two trials examining repaglinide $[49,50]$.

Treatments used in the observational studies were quite heterogeneous, with some studies even combining patients using various combinations of OADs and/or insulin and/or diet alone into a single group [51-57] (Table 2).

\section{Eligibility, Number, and Comparability of Patients}

In the RCTs, the number of subjects varied from 41 to 1066. Inclusion and exclusion criteria were mentioned in some way for all RCTs, but the level of details presented varied greatly. All of the RCTs described prior diabetes treatments, and most of the trials enrolled subjects previously treated with metformin or sulfonylurea either as monotherapy or in combination. However, in a few trials, a minority of patients had been treated with thiazolidinediones, glinides, or acarbose (Table 1). A specific cutoff for glycemic control $\left(\mathrm{HbA}_{1 \mathrm{c}}\right)$ for eligibility was only specified for four RCTs (7-10\% [34]; 6.5-12.0\% [33]; $\leq 8.5 \%$ [38]; $\leq 10 \%[46,47])$. One trial indicated that participants had to be "well controlled" [45]. Most $(n=7 / 10)$ trials excluded patients with a history of recurrent hypoglycemia, severe hypoglycemia, or hypoglycemia unawareness $[33,45-48,50]$, but others made no such exception [38, 39, 49]. Exclusion of patients with at least some serious systemic diseases was reported in all but three trials, but the level of stringency reported varied [39, 47, 49].

There was also a considerable range in the number of patients participating in the observational studies (23-1333 patients; Table 2). With the exception of four reports $[54-56,58]$, all of the observational studies mentioned patient inclusion/exclusion criteria to some extent. However, as with RCTs, the stringency of these criteria varied considerably among studies. For example, some studies indicated that all patients with T2D were included [51] or that all consecutive patients were enrolled [52], whereas others specified more detailed inclusion criteria such as age, type of prior treatment, and/or willingness to fast. Most studies did not specify any $\mathrm{HbA}_{1 \mathrm{c}}$ cutoff for eligibility, although one required $\mathrm{HbA}_{1 \mathrm{c}} \leq 9.0 \%$ [29], two required $\mathrm{HbA}_{1 \mathrm{c}} \leq 8.5 \%$ $[40,43]$, one required $\mathrm{HbA}_{1 \mathrm{c}} \leq 8.0 \%$ [41], and one just indicated that patients had to be in "good control" [59].

The same variation was noted with respect to exclusion criteria, with some observational studies indicating no exclusion criteria other than insulin treatment (e.g., $[44,60]$ ) and others listing very specific exclusion criteria (e.g., duration of diabetes, level of glycemic control, prior treatments, incomplete fasting, incomplete medical records, and/or serious renal, hepatic, cerebrovascular or cardiovascular disease, pregnancy or lactation; retinopathy, and uncontrolled hypertension $[29,40,41,53,61,62])$. In contrast to the RCTs, few observational studies mentioned excluding patients with severe hypoglycemia [57], recurrent hypoglycemia [61, 62], or hypoglycemia unawareness [63], but otherwise this appeared uncommon. One study using continuous glucose monitoring (CGM) 
indicated that "low-risk" patients were enrolled [61].

\section{Choice and Measurement of End Points}

The critical factor of end points was not consistent across studies, either with respect to the choice or efficacy or safety as a primary end point, or how those end points were measured. Three RCTs used a primary efficacy end point $[34,49,50]$ and four RCTs indicated that the primary end point was a safety end point [38, 45-47], and in two, a primary end point was not explicitly stated or clear, with multiple efficacy and safety end points being listed $[39,48]$. In one trial, a specific composite end point was used [33] (Table 1). In some studies where efficacy was indicated to be the primary end point, safety end points were also included. Conversely, in some studies where safety was listed as the primary end point, some efficacy measures were also reported.

When glycemic efficacy end points were reported, there were also considerable differences in how they were measured, ranging from CGM to self-monitored blood glucose (SMBG), to clinic visits with laboratory measures, to patient diaries with or without review by a physician, to phone interviews and retrospective review of medical records. Secondary end points such as weight change, blood pressure, lipids, and quality of life were inconsistently reported.

\section{Definition of Safety (Hypoglycemia) Outcomes}

In the RCTs, the definition of hypoglycemia, as well as how hypoglycemia was measured, varied. Two trials used symptoms only [47, 50]. When a cutoff value was mentioned, most trials specified a value of $<3.9$ or $\leq 3.9 \mathrm{mmol} / \mathrm{L}$, although two trials utilized other values $(<3.1 \mathrm{mmol} / \mathrm{L}$ [49] and $<2.8 \mathrm{mmol} / \mathrm{L}$ [50]; Table 1). In one trial, the cutoff point was unclear [45]. There were also cases where a primary end point used symptoms as the criteria, but the results for additional hypoglycemic end points were also reported (e.g., $[46,47])$.

There was also considerable variability in how hypoglycemia was defined and measured in the observational studies (Table 2). Some studies used patient-reported symptoms only $[29,51,57,60]$, but more typically used symptoms with or without blood glucose (BG) measurements [40, 41, 43, 44, 52, 56, 62]. In one of these cases, the cutoff was not specified [56]. The BG cutoff values used were also heterogeneous $(<3.9 \mathrm{mmol} / \mathrm{L}[40] ; \leq 3.9 \mathrm{mmol} / \mathrm{L}$ [41]; 2.8-3.9 mmol/L [53]; $<3.9 \mathrm{mmol} / \mathrm{L} \quad$ [42]; $<3.88 \mathrm{mmol} / \mathrm{L} \quad$ [61]; $\quad<3.9 \mathrm{mmol} / \mathrm{L} \quad$ [43]; $<3.5 \mathrm{mmol} / \mathrm{L}$ [44]).

\section{Duration of Treatment and Follow-Up}

There was great variation in the amount of time patients were assessed, treated, and followed across studies. In the RCTs (Table 1), the run-in period for the non-sulfonylurea treatment varied considerably, even where patients were switching to the identical drug. For example, Anwar et al. [49] reported a 3-month run-in period for patients switching to repaglinide, whereas Mafauzy [50] reported 6 weeks. For three trials using incretins, one with vildagliptin [39] and two with sitagliptin [46, 47], the duration of the run-in period was unclear. The duration of follow-up post-Ramadan, when fasting ceased and normal diet and lifestyle patterns resumed, was also variable and sometimes difficult to discern. For the observational studies (Table 2), there was also great variation in the length of 
time during which patients were assessed and data obtained.

\section{Blinding Protocols}

Blinding of subjects and evaluators during a clinical trial is considered an important protection against bias. Of the 10 RCTs, only two trials were blinded [38, 48] (Table 1). One was a double-blind, double-dummy trial [38], and the other was double-blinded [48]. By definition, blinding was not possible in the observational studies.

\section{Definition and Characteristics of Fasting}

Fasting was not always explicitly defined in studies. In the RCTs, the intent to fast was either stated or assumed based on screening criteria in nine out of ten trials, but only one trial indicated a specific minimum amount of time (i.e., at least 10 days) for fasting [33]. One trial indicated that participants would be excluded if they expected to break their fast for $>3$ days [50]. It has been reported that the ability to keep a fast may also depend on the type of treatment [64], but this was not regularly reported and, when reported, not in sufficient detail to allow for meaningful interpretation of the likely impact of non-adherence on treatment. Adherence to fasting was not described for six RCTs [33, 34, 45, 48-50]. When adherence was reported, the statistic used varied (Table 1 ). For example, one study reported the mean number of days of fasting for the two treatment groups (i.e., $28.3 \pm 3.0$ and $28.1 \pm 3.8$ days) [38], whereas two other trials reported the proportion of people in each treatment group who did not break their fast except to treat symptoms of hypoglycemia (i.e., $89.7 \%$ to $98.4 \%$ of participants) $[46,47]$. It was often unclear what constituted an interruption of fasting, whether an interruption was temporary or permanent, or under what circumstances an interruption might be of sufficient duration to be considered a break in the fast (non-adherence). For example, one RCT indicated that eight individuals in one of the treatment arms broke their fast, but did not quantify or otherwise describe what that meant [39].

In the observational studies, intention to fast (or actual fasting) during Ramadan was either an implicit or explicit inclusion criteria. In some cases, the period of intending to fast was pre-specified in some detail ( $>10$ days $[43,55$, 57]; $\geq 15$ days [61]; $\geq 20$ days [61]; or throughout Ramadan [59, 62]). In general, there was more attention to describing adherence to fasting in the observational studies, with $13 / 20$ studies reporting some measure of adherence (Table 2 ). This was most frequently framed as the mean number of days of fasting. However, an inspection of these mean values in the table (e.g., from approximately 20.4 to 28.6 days) makes it clear that some participants did not fast the entire month of Ramadan.

\section{Ramadan-focused Education and Quality of Life Assessment}

The potential value of patient education has been evaluated in a number of clinical studies. For example, patients with T2D using OADs who received a Ramadan-focused education and awareness in diabetes (READ) program demonstrated a decrease in hypoglycemic episodes during Ramadan [65]. Another comparative trial in Thailand showed that patients in the group receiving education prior to Ramadan significantly reduced the number of hypoglycemic episodes $(P=0.013)$, diastolic blood pressure, $(P=0.041)$, and consumption 
of sweetened food $(P=0.002)$, and the number of patients with hypoglycemic symptoms was also lower $(P=0.013)$ [66]. A comparison of patients recruited from clinics in four Muslim nations who received an individualized educational program vs. those who did not showed significant improvements in a variety of diabetes management outcomes, such as modifying their treatment plan $(P<0.001)$, performing SMBG at least twice daily $(P<0.0001)$, and having improved knowledge about hypoglycemic signs and symptoms $(P=0.0007), \quad$ as well as fewer severe hypoglycemic events $(P=0.0017)$ [67]. One uncontrolled study described the practicality of implementing a Ramadan-specific educational program through diabetes-specialist centers [68]. The study reported that drug dose and timing were modified in $90.5 \%$ of patients with T2D.

The extent to which Ramadan-focused education is included in trials whose primary goal is to compare drug treatment regimens is unclear. Among the randomized trials summarized in Table 1, only one study explicitly mentioned providing Ramadan-focused education, which was given to patients in both arms of the trial [38]. However, two other trials mentioned providing medical counseling regarding risks of hypoglycemia during fasting [46, 47]. It is unclear to what degree these issues may have been raised during the routine informed consent process in other trials. Among the observational studies (Table 2), three mentioned providing Ramadan-focused advice about diabetes management [42, 44] or information about the risks associated with fasting [62], again provided to all patients participating in the studies. Future trials should explicitly include and describe the extent of Ramadan-focused education for participants.

With regard to patient-reported outcomes and quality of life assessment, only one of the reviewed studies assessed treatment satisfaction and one assessed lifestyle changes [56, 69].

\section{Reporting of Diet and Exercise}

Changes in diet and exercise were reported infrequently, and when reported, typically, this was not in sufficient detail to enable adequate account for confounding effects of these changes when evaluating the efficacy and/or safety of the treatments being studied. Only one RCT provided such data, with physical activity assessed by the International Physical Activity Questionnaire (IPAQ), and diet information reported in the form of changes in score for total Metabolic Equivalent Tasks (METS) for each treatment group [33].

Among the observational studies, as with the RCTs, reporting of data on diet and exercise was very limited, with only $3 / 20$ studies providing information. Siaw et al. [57] reported general trends in diet and exercise during Ramadan, describing these only as "more," "less," or "unchanged". An analysis of the proportion of patients reporting reduction $(64.7 \%)$, increase (5.9\%), or no changes (29.4\%) in dietary intake, as well as data on physical exercise, indicated that there were no significant associations between these categories and improvements in mean $\mathrm{HbA}_{1 \mathrm{c}}$ during fasting. Sahin et al. [56] also reported similar categorical groupings of changes in diet and exercise, whereas Ahmadani et al. [51] reported caloric intake for 1 day before and after fasting, in addition to a simple dichotomous outcome of diet having changed or not and exercise having changed or not. In some cases when it was mentioned in the Methods section of a paper that information 
on diet and/or exercise was obtained from patients, the results for those variables were not presented in the trial report. For example, Bonakdaran et al. [61] indicated that patients were required to record dietary programs, time of meals, quality and quantity of meals, and time and extent of exercise, but those data were neither reported nor apparently factored into the analysis of BG readings or hypoglycemic events. Zargar et al. [29] also mentioned that data on meals were obtained, but no results were presented.

\section{Classes of Diabetes Treatments Studied}

The 10 RCTs were heterogeneous with respect to diabetes treatments evaluated, with five comparing sulfonylureas to DPP-4 inhibitors, two comparing sulfonylureas to GLP-1 analogs, two comparing sulfonylurea to repaglinide, and one comparing sulfonylurea to pioglitazone (Table 1). In some cases, only one sulfonylurea was used, and in others, a variety of sulfonylureas was permissible. Use of metformin was inconsistent, with some trials allowing it, others mandating it, and others excluding metformin. No RCTs have compared receptor GLP-1 receptor agonists and DPP-4 inhibitors head-to-head in the treatment of T2D during Ramadan. This is in contrast to at least seven such studies published in patients with T2D not focused on Ramadan fasting (see [70]). Being a more recently introduced class of drugs, sodium-glucose co-transporter 2 inhibitors have not yet been studied in fasting patients with T2D during Ramadan.

Observational studies were even more heterogeneous with respect to the treatments studied and it was not uncommon to group together patients using treatments ranging from lifestyle management to OADs to insulin, either individually or in combination (Table 2).

\section{Adherence to Treatment}

In the RCTs, adherence to treatment was difficult to discern. One RCT reported the proportion of missed doses [38], and others reported the proportion of patients who changed the dose or timing of their medication [46, 47]. One study reported the proportion of completers reaching the optimal dose [49], and another reported the proportion of patients exposed to treatment for $>6$ and $>10$ weeks [50].

Limited reporting of adherence to treatment was also typical in the observational studies. When mentioned (6/20 studies), this was usually brief and in the form of proportion of patients with missed doses, proportion making adjustments to dose, or changes in the timing of dose (e.g., [43, 51, 54, 56, 57, 60]). Few studies provided detailed measures of adherence (e.g., overall adherence per treatment group, proportion of patients with treatment change in each group, type of treatment change, number of times the treatment was not taken, and/or number of times the treatment was not taken due to hypoglycemia or fear of hypoglycemia) [40, 41]. Across these studies, analysis of how these various measures of adherence to each treatment were related to the frequency of hypoglycemic events was generally lacking.

\section{DISCUSSION}

The studies reviewed here, conducted in populations of Muslims with T2D who fasted during Ramadan, were quite heterogeneous in critical components of their design, including but not limited to patient eligibility and exclusion criteria, glucose control and treatments at entry, choice of outcomes assessed and definitions of those outcomes, 
and method and timing of outcomes assessment, all of which significantly limit the ability to compare results across trials. This was true for RCTs as well as for the observational studies. Compared with typical diabetes trials in non-Muslim/non-fasting patients, there appears to be a trend for trials during Ramadan to emphasize safety end points over efficacy end points. The choice of either an efficacy or safety measure as the primary end point also has bearing, because a primary end point may be used for power calculation, which may result in a study being underpowered to capture other end points. Efficacy and safety should be included in the reporting of data, so that comprehensive information is made available to clinicians to support clinical decision making.

With respect to efficacy, the choice of end point and measurement method should be aligned with the duration of the trial and follow-up period. $\mathrm{HbA}_{1 \mathrm{c}}$ is the standard efficacy end point used in the majority of longer duration clinical trials and can be reliably and easily measured. $\mathrm{HbA}_{1 \mathrm{c}}$ reflects glycemia over the lifespan of red blood cells, but predominantly glycemia during $6-8$ weeks prior to the time of measurement. This is a period substantially longer than the duration of fasting during Ramadan. By comparison, fructosamine has the ability to assess glycemic control during shorter periods of assessment compared to $\mathrm{HbA}_{1 \mathrm{c}}$, as it reflects average glycemia the preceding $1-3$ weeks $[71,72]$. Although fructosamine is not widely used in clinical trials, it has been used as the primary end point in a recent RCT with liraglutide, so clinicians may become more familiar and comfortable using it [34]. Another validated short-term marker for glycemic control, especially for recent postprandial hyperglycemic excursions and glycemic variability, is 1,5-anhydroglucitol [73, 74]. Ambulatory glucose monitoring and CGM offer the possibility of very precise characterization of daily blood glucose excursions and allows the possibility of assessing those changes in light of changes in diet. The choice of CGM as a tool will need to be balanced against the increased cost and complexity associated with its use.

With respect to safety, one obvious concern for patients with T2D taking glucose-lowering medications during fasting is the risk of hypoglycemia. Having a precise, accurate, and uniform method of assessing hypoglycemia, as well as clearly defined cut points, is important for being able to evaluate trial results and to compare across trials. Similar entry criteria with respect to history of hypoglycemia or hypoglycemia unawareness are essential for comparing the results of different studies.

Understanding diet and exercise patterns associated with diabetes treatment is particularly important for trials conducted during Ramadan, given that prolonged fasting involves major changes in routine eating habits and/or the timing of exercise that may affect glycemic control. Few of the studies summarized here reported any diet and exercise outcomes, and those that did categorized diet and exercise patterns very fundamentally (e.g., as increased, decreased, unchanged) [56, 57]. Such an approach may be overly simplistic and not capture important features of changes in diet or exercise. Furthermore, use of a limited number of discreet categories would tend to render any adjustment for confounding by those factors imprecise, although it should be noted that such an adjustment was not reported in any of the trials. How to best assess and control for changes in diet when the frequency, content, 
and volume of meals may change substantially over the study period is an unanswered question. Thorough dietary assessment involves techniques such as $24-\mathrm{h}$ recall and food frequency questionnaires (e.g., [75]), which may be cumbersome to add to a conventional trial already assessing efficacy and safety measures.

Adherence to fasting and duration of the actual fast are important to determine when studying the effects of treatment on glucose control. As noted in several studies, patient-initiated changes in medication timing or dose, or discontinuation of treatment during Ramadan, is common [28, 29]. However, adherence to treatment was often not reported, and when reported was typically not assessed relative to the outcome of interest, regardless of whether efficacy and/or safety measures were used. It is also critical to differentiate a stated intention to fast (which is typically a criterion for enrollment in a RCT) versus the actual fasting behavior during Ramadan. For example, the EPIDAIR study reported that the proportion of subjects fasting $\geq 15$ days ranged from $57.8 \%$ in Turkey to $89.8 \%$ in Malaysia and Bangladesh [1]. It is sometimes mentioned that participants may periodically interrupt their fast temporarily if symptoms of hypoglycemia are experienced, but the duration of the interruption may not be specified [68]. As reviewed here, at the time of enrollment/screening, some patients may indicate an intention to fast throughout the entire month of Ramadan, whereas others may indicate fasting may not last the entire month. With respect to adherence, the actual duration of fasting may vary from the stated intention and be considerably less than the full month of Ramadan.

\section{CONCLUSIONS}

In part due to the degree of heterogeneity in key aspects of the study design from both RCTs and observational studies, comparability across studies remains difficult. Thus, the ideal treatment regimen for patients with T2D during Ramadan has not yet been identified. Given the unique challenges of managing diabetes during fasting, desirable characteristics of any treatment might include flexibility in timing of administration and/or once-daily dosing (so as not to conflict with prohibitions during the daytime hours when taking medications is not possible due to religious concerns), and a low risk of hypoglycemia (to better accommodate the prolonged period of fasting each day).

More definitive trials during Ramadan fasting, using more evolved trial designs (e.g., [34]), are needed to answer important clinical questions. Trials should include data on a full range of important clinical end points (e.g., glycemic control, hypoglycemia, hyperglycemia, other adverse events, lipid levels, blood pressure) and quality of life, and use clearly defined measures that are appropriate to these end points and time frame. Detailed assessment of potentially confounding variables such as changes in diet and exercise are also required so that appropriate adjustment for these factors can be performed when assessing outcomes. Ideally, some trials should also involve head-to-head comparisons between DPP-4 inhibitors and GLP-1 analogs. Despite the limitations of many published studies, there is evidence suggesting that newer drugs having a lower risk of hypoglycemia (such as those of the incretin class) may be beneficial for patients who choose to fast during Ramadan [30, 31, 34, 76]. 


\section{ACKNOWLEDGMENTS}

No funding or sponsorship was received for this study or publication of this article, other than that declared below. The authors are grateful to Gary Patronek, Ph.D. of Watermeadow Medical, $\mathrm{UK}$, for editorial writing assistance in the development of this manuscript. This assistance was funded by Novo Nordisk AG, which also had a role in the review of the manuscript for scientific accuracy. All named authors meet the International Committee of Medical Journal Editors (ICMJE) criteria for authorship for this manuscript, take responsibility for the integrity of the work as a whole, and have given final approval to the version to be published. The article processing charges for this publication were funded by Novo Nordisk AG.

Disclosures. Saud Al Sifri and Kashif Rizvi have no conflicts of interest to disclose.

Compliance with Ethics Guidelines. This article is based on previously conducted studies, and does not involve any new studies of human or animal subjects performed by any of the authors.

Open Access. This article is distributed under the terms of the Creative Commons Attribution-NonCommercial 4.0 International License (http://creativecommons.org/licenses/ by-nc/4.0/), which permits any noncommercial use, distribution, and reproduction in any medium, provided you give appropriate credit to the original author(s) and the source, provide a link to the Creative Commons license, and indicate if changes were made.

\section{REFERENCES}

1. Salti I, Benard E, Detournay B, EPIDIAR study group, et al. A population-based study of diabetes and its characteristics during the fasting month of Ramadan in 13 countries: results of the epidemiology of diabetes and Ramadan 1422/2001 (EPIDIAR) study. Diabetes Care. 2004;27:2306-11.

2. Al-Arouj M, Assaad-Khalil S, Buse J, et al. Recommendations for management of diabetes during Ramadan: update 2010. Diabetes Care. 2010;33:1895-902.

3. Al Maatouq MA. Pharmacological approaches to the management of type 2 diabetes in fasting adults during Ramadan. Diabetes Metab Syndr Obes. 2012;5:109-19.

4. Ghouri N, Gatrad R, Sattar N, Dhami S, Sheikh A. Summer-winter switching of the Ramadan fasts in people with diabetes living in temperate regions. Diabet Med. 2012;29:696-7.

5. Roky R, Houti I, Moussamih S, Qotbi S, Aadil N. Physiological and chronobiological changes during Ramadan intermittent fasting. Ann Nutr Metab. 2004;48:296-303.

6. Ahmad J, Pathan MF, Jaleel MA, et al. Diabetic emergencies including hypoglycemia during Ramadan. Indian J Endocrinol Metab. 2012;16:512-5.

7. Benaji B, Mounib N, Roky R, et al. Diabetes and Ramadan: review of the literature. Diabetes Res Clin Pract. 2006;73:117-25.

8. Beshyah SA. Fasting during the month of Ramadan for people with diabetes: medicine and Fiqh united at last. Ibnosina J Med Biomed Sci. 2009;1:58-60.

9. M'guil M, Ragala MA, El Guessabi L, et al. Is Ramadan fasting safe in type 2 diabetic patients in view of the lack of significant effect of fasting on clinical and biochemical parameters, blood pressure, and glycemic control? Clin Exp Hypertens. 2008;30:339-57.

10. Jawad F, Kalra S. Diabetes care in Ramadan: an exemplar of person centered care. J Pak Med Assoc. 2015;65(5 Suppl 1):S1-2.

11. Hassan A, Meo SA. Diabetes during Ramadan: underestimated, under-investigated, needs more 
attention. Eur Rev Med Pharmacol Sci. 2014;18:3528-33.

12. PEW Research Center. The future of world religions: population growth projections, 2010-2050. April 2, 2015. Retrieved from: http://www.pewforum. org/2015/04/02/religious-projections-2010-2050/. Accessed 15 Jan 2016.

13. Inzucchi SE, Bergenstal RM, Buse JB, et al. Management of hyperglycemia in type 2 diabetes, 2015: a patient-centered approach: update to a position statement of the American Diabetes Association and the European Association for the Study of Diabetes. Diabetes Care. 2015;38:140-9.

14. Rodbard HW, Jellinger PS, Davidson JA, et al. Statement by an American Association of Clinical Endocrinologists/American College of Endocrinology consensus panel on type 2 diabetes mellitus: an algorithm for glycemic control. Endocr Pract. 2009;15:540-59.

15. Ahmed MH, Abdu TA. Diabetes and Ramadan: an update on use of glycemic therapies during fasting. Ann Saudi Med. 2011;31:402-6.

16. Al-Arouj $\mathrm{M}$, Bouguerra $\mathrm{R}$, Buse $\mathrm{J}$, et al. Recommendations for management of diabetes during Ramadan. Diabetes Care. 2005;28:2305-11.

17. Bashir MI, Pathan MF, Raza SA, et al. Role of oral hypoglycemic agents in the management of type 2 diabetes mellitus during Ramadan. Indian J Endocrinol Metab. 2012;16:503-7.

18. Beshyah S, Benbarka M, Sherif I. Practical management of diabetes during Ramadan fast. Libyan J Med. 2007;2:185-9.

19. Diabetes UK. Ramadan and diabetes. September 2004/Retrieved from: https://www.diabetes.org.uk/ Documents/Languages/English/Ramadan_Eng.pdf. Accessed 15 Jan 2016.

20. Hui E, Devendra D. Diabetes and fasting during Ramadan. Diabetes Metab Res Rev. 2010;26:606-10.

21. Ibrahim $\mathrm{M}$, Abu Al Magd $\mathrm{M}$, et al. Recommendations for management of diabetes during Ramadan: update 2015. BMJ Open Diabetes Res Care. 2015;3:e000108.

22. Jaleel MA, Raza SA, Fathima FN, Jaleel BN. Ramadan and diabetes: as-Saum (the fasting). Indian J Endocrinol Metab. 2011;15:268-73.

23. Karamat MA, Syed A, Hanif W. Review of diabetes management and guidelines during Ramadan. J R Soc Med. 2010;103:139-47.
24. Pathan MF, Sahay RK, Zargar AH, et al. South Asian Consensus Guideline: use of GLP-1 analogue therapy in diabetes during Ramadan. Indian J Endocrinol Metab. 2012;16:525-7.

25. Velayudhan M. Managing diabetes during the Muslim fasting month of Ramadan. Med J Malaysia. 2012;67:353-4 (quiz 355).

26. Hakeem R, Ahmedani MY, Alvi SF, Ulhaque MS, Basit A, Fawwad A. Dietary patterns and glycemic control and compliance to dietary advice among fasting patients with diabetes during Ramadan. Diabetes Care. 2014;37:e47-8.

27. Aadil N, Houti IE, Moussamih S. Drug intake during Ramadan. BMJ. 2004;329:778-82.

28. Babineaux SM, Toaima D, Boye $\mathrm{KS}$, et al. Multi-country retrospective observational study of the management and outcomes of patients with Type 2 diabetes during Ramadan in 2010 (CREED). Diabet Med. 2015;32:819-28.

29. Zargar AH, Siraj M, Jawa AA, Hasan M, Mahtab H. Maintenance of glycaemic control with the evening administration of a long acting sulfonylurea in male type 2 diabetic patients undertaking the Ramadan fast. Int J Clin Pract. 2010;64:1090-4.

30. Gray LJ, Dales J, Brady EM, Khunti K, Hanif W, Davies MJ. Safety and effectiveness of non-insulin glucose-lowering agents in the treatment of people with type 2 diabetes who observe Ramadan: a systematic review and meta-analysis. Diabetes Obes Metab. 2015;17:639-48.

31. Schweizer A, Halimi S, Dejager S. Experience with DPP-4 inhibitors in the management of patients with type 2 diabetes fasting during Ramadan. Vasc Health Risk Manag. 2014;10:15-24.

32. Mbanya JC, Al-Sifri S, Abdel-Rahim A, Satman I. Incidence of hypoglycemia in patients with type 2 diabetes treated with gliclazide versus DPP-4 inhibitors during Ramadan: a meta-analytical approach. Diabetes Res Clin Pract. 2015;109:226-32.

33. Brady EM, Davies MJ, Gray LJ, et al. A randomized controlled trial comparing the GLP-1 receptor agonist liraglutide to a sulfonylurea as add on to metformin in patients with established type 2 diabetes during Ramadan: the Treat 4 Ramadan Trial. Diabetes Obes Metab. 2014;16:9.

34. Azar ST, Echtay A, Wan Bebakar WM, et al. Efficacy and Safety of Liraglutide vs. Sulfonylurea Both in Combination with Metformin during Ramadan in Subjects with Type 2 Diabetes (LIRA-Ramadan): A Randomized Trial. Diabetes. 2015;64 Supplement 1 A288. 
35. General practice notebook-a UK medical reference. Sulfonylurea s. 2015. http://www. gpnotebook.co.uk/simplepage.cfm?ID=1597308955. Accessed 15 Jan 2016.

36. Hassanein M, Abdallah $\mathrm{K}$, Schweizer A. A double-blind, randomized trial, including frequent patient-physician contacts and Ramadan-focused advice, assessing vildagliptin and gliclazide in patients with type 2 diabetes fasting during Ramadan: the STEADFAST study. Vasc Health Risk Manag. 2014;10:319-26.

37. Landman GW, de Bock GH, van Hateren $\mathrm{KJ}$, et al. Safety and efficacy of gliclazide as treatment for type 2 diabetes: a systematic review and meta-analysis of randomized trials. PLoS One. 2014;9:e82880.

38. Mbanya JC, Al-Sifri S, Abdel-Rahim A, Satman I. Incidence of hypoglycemia in patients with type 2 diabetes treated with gliclazide versus DPP-4 inhibitors during Ramadan: a meta-analytical approach. Diabetes Res Clin Pract. 2015;109:226-32.

39. Malha LP, Taan G, Zantout MS, Azar ST. Glycemic effects of vildagliptin in patients with type 2 diabetes before, during and after the period of fasting in Ramadan. Ther Adv Endocrinol Metab. 2014;5:6

40. Al-Arouj M, Hassoun AA, Medlej R, et al. The effect of vildagliptin relative to sulfonylurea s in Muslim patients with type 2 diabetes fasting during Ramadan: the VIRTUE study. Int J Clin Pract. 2013;67:957-63.

41. Halimi S, Levy M, Huet D, Quere S, Dejager S. Experience with vildagliptin in type 2 diabetic patients fasting during Ramadan in France: insights from the VERDI study. Diabetes Ther. 2013;4:385-98.

42. Shete A, Shaikh A, Nayeem KJ, et al. Vildagliptin vs sulfonylurea in Indian Muslim diabetes patients fasting during Ramadan. World J Diabetes. 2013;4:358-64.

43. Hassanein M, Hanif W, Malik W, et al. Comparison of the dipeptidyl peptidase- 4 inhibitor vildagliptin and the sulfonylurea gliclazide in combination with metformin, in Muslim patients with type 2 diabetes mellitus fasting during Ramadan: results of the VECTOR study. Curr Med Res Opin. 2011;27:1367-74.

44. Devendra D, Gohel B, Bravis V, et al. Vildagliptin therapy and hypoglycaemia in Muslim type 2 diabetes patients during Ramadan. Int $\mathrm{J}$ Clin Pract. 2009;63:1446-50.

45. Abid R. To compare the hypoglycaemic effect of sitagliptin/metformin combination vs.glimiperide in type II diabetes patients during Ramadan. Med Forum Mon. 2013;24:4.

46. Aravind SR, Ismail SB, Balamurugan $\mathrm{R}$, et al. Hypoglycemia in patients with type 2 diabetes from India and Malaysia treated with sitagliptin or a sulfonylurea during Ramadan: a randomized, pragmatic study. Curr Med Res Opin. 2012;28:1289-96.

47. Al Sifri S, Basiounny A, Echtay A, et al. The incidence of hypoglycaemia in Muslim patients with type 2 diabetes treated with sitagliptin or a sulfonylurea during Ramadan: a randomised trial. Int J Clin Pract. 2011;65:1132-40.

48. Vasan S, Thomas N, Bharani AM, et al. A double-blind, randomised, multicenter study evaluating the effects of pioglitazone in fasting Muslim subjects during Ramadan. Int J Diab Dev Ctries. 2006;26:7.

49. Anwar A, Azmi KN, Hamidon BB, Khalid BA. An open label comparative study of glimepiride versus repaglinide in type 2 diabetes mellitus Muslim subjects during the month of Ramadan. Med J Malaysia. 2006;61:8.

50. Mafauzy M. Repaglinide versus glibenclamide treatment of type 2 diabetes during Ramadan fasting. Diabetes Res Clin Pract. 2002;58:45-53.

51. Ahmadani MY, Riaz M, Fawwad A, Hydrie MZ, Hakeem R, Basit A. Glycaemic trend during Ramadan in fasting diabetic subjects: a study from Pakistan. Pak J Biol Sci. 2008;11:2044-7.

52. Elmehdawi RR, Mukhtad NA, Allaghi NI, Elmajberi SJ. Fasting of Ramadan in peoples with diabetes in Benghazi, Libya: an exploratory study. Libyan J Med. 2010;. doi:10.3402/ljm.v5i0.5036 [Epub ahead of print].

53. Karatoprak C, Yolbas S, Cakirca M, et al. The effects of long term fasting in Ramadan on glucose regulation in type 2 diabetes mellitus. Eur Rev Med Pharmacol Sci. 2013;17:2512-6.

54. Lessan N, Hasan H, Barakat MT. Ramadan fasting: a study of changes in glucose profiles among patients with diabetes using continuous glucose monitoring. Diabetes Care. 2012;35:e37.

55. Norouzy A, Mohajeri SM, Shakeri S, et al. Effect of Ramadan fasting on glycemic control in patients with type 2 diabetes. J Endocrinol Invest. 2012;35:766-71.

56. Sahin SB, Ayaz T, Ozyurt N, Ilkkilic K, Kirvar A, Sezgin $\mathrm{H}$. The impact of fasting during Ramadan on the glycemic control of patients with type 2 diabetes mellitus. Exp Clin Endocrinol Diabetes. 2013;121:531-4. 
57. Siaw MY, Chew DE, Dalan R, et al. Evaluating the effect of Ramadan fasting on muslim patients with diabetes in relation to use of medication and lifestyle patterns: a prospective study. Int J Endocrinol. 2014;2014:308546.

58. Uysal AR, Erdoğan MF, Sahin G, Kamel N, Erdoğan G. Clinical and metabolic effects of fasting in 41 type 2 diabetic patients during Ramadan. Diabetes Care. 1998;21:2033-4.

59. Glimepiride in Ramadan (GLIRA) Study Group. The efficacy and safety of glimepiride in the management of type 2 diabetes in Muslim patients during Ramadan. Diabetes Care. 2005;28:421-2.

60. Aravind SR, Al Tayeb K, Ismail SB, 2009 Ramadan Study Group, et al. Hypoglycaemia in sulfonylurea-treated subjects with type 2 diabetes undergoing Ramadan fasting: a five-country observational study. Curr Med Res Opin. 2011;27:1237-42.

61. Bonakdaran SH, Khajeh-Dalouie M. The effects of fasting during Ramadan on glycemic excursions detected by continuous glucose monitoring system (CGMS) in patients with type 2 diabetes. Med J Malaysia. 2011;66:447-50.

62. Cesur M, Corapcioglu D, Gursoy A, et al. A comparison of glycemic effects of glimepiride, repaglinide, and insulin glargine in type 2 diabetes mellitus during Ramadan fasting. Diabetes Res Clin Pract. 2007;75:141-7.

63. Sari R, Balci MK, Akbas SH, Avci B. The effects of diet, sulfonylurea, and repaglinide therapy on clinical and metabolic parameters in type 2 diabetic patients during Ramadan. Endocr Res. 2004;30:169-77.

64. Fatima J, Karoli R, Chandra A, Naqvi N. Attitudinal determinants of fasting in type 2 diabetes mellitus patients during Ramadan. J Assoc Phys India. 2011;59:630-4.

65. Bravis V, Hui E, Salih S, Mehar S, Hassanein M, Devendra D. Ramadan Education and Awareness in Diabetes (READ) programme for Muslims with type 2 diabetes who fast during Ramadan. Diabet Med. 2010;27:327-31.

66. Susilparat P, Pattaraarchachai J, Songchitsomboon $S$, Ongroongruang S. Effectiveness of contextual education for self-management in Thai Muslims with type 2 diabetes mellitus during Ramadan. J Med Assoc Thai. 2014;97(Suppl 8):S41-9.
67. McEwen LN, Ibrahim M, Ali NM, et al. Impact of an individualized type 2 diabetes education program on clinical outcomes during Ramadan. BMJ Open Diabetes Res Care. 2015;3:e000111.

68. Ahmedani MY, Alvi SF, Haque MS, Fawwad A, Basit A. Implementation of Ramadan-specific diabetes management recommendations: a multi-centered prospective study from Pakistan. J Diabetes Metab Disord. 2014;13:37.

69. Ahmedani MY, Haque MS, Basit A, Fawwad A, Alvi SF. Ramadan Prospective Diabetes Study: the role of drug dosage and timing alteration, active glucose monitoring and patient education. Diabet Med. 2012;29:709-15.

70. Brunton S. GLP-1 receptor agonists vs DPP-4 inhibitors for type 2 diabetes: is one approach more successful or preferable than the other? Int J Clin Pract. 2014;68:557-67.

71. Malmström H, Walldius G, Grill V, Jungner I, Hammar N. Fructosamine is a risk factor for myocardial infarction and all-cause mortalitylongitudinal experience from the AMORIS cohort. Nutr Metab Cardiovasc Dis. 2015;25(10):943-50.

72. Parrinello CM, Selvin E. Beyond HbA1c and glucose: the role of nontraditional glycemic markers in diabetes diagnosis, prognosis, and management. Curr Diab Rep. 2014;14:548.

73. Dungan KM. 1,5-anhydroglucitol (GlycoMark) as a marker of short-term glycemic control and glycemic excursions. Expert Rev Mol Diagn. 2008;8:9-19.

74. Kim WJ, Park CY. 1,5-Anhydroglucitol in diabetes mellitus. Endocrine. 2013;43:33-40.

75. Vasan SK, Karol R, Mahendri NV, Arulappan N, Jacob JJ, Thomas N. A prospective assessment of dietary patterns in Muslim subjects with type 2 diabetes who undertake fasting during Ramadan. Indian J Endocrinol Metab. 2012;16:552-7.

76. Aziz KM. Fasting during Ramadan: efficacy, safety, and patient acceptability of vildagliptin in diabetic patients. Diabetes Metab Syndr Obes. 2015;8:207-11.

77. Belkhadir J, el Ghomari H, Klöcker N, Mikou A, Nasciri M, Sabri M. Muslims with non-insulin dependent diabetes fasting during Ramadan: treatment with glibenclamide. BMJ. 1993;307:292-5. 